\title{
FOTO-GRAFIAS: REPRODUTIBILIDADE, TÉCNICA E O RECORTE DA HISTÓRIA NA ESCRITA NO EXISTENTE
}

\author{
Rochelly Rodrigues Holanda \\ Marco César de Souza Melo \\ Tadeu Lucas de Lavor Filho \\ Deborah Christina Antunes
}

\begin{abstract}
RESUMO
O objetivo deste ensaio é refletir sobre a relação entre a produção técnica de imagens e suas reverberações político-sociais no presente. Utilizaremos como referencial principal as ideias de Walter Benjamin, especialmente a partir dos processos de tecnificação das produções de arte e da crítica social implicada nesses processos, em diálogo com pensadores como Vilém Flusser, Roland Barthes e Susan Sontag. Como elemento de tematização tomaremos fotografias como o "Menino na praia de Copacabana no réveillon em 2018" de Lucas Landau e "Memory Lane" do projeto Babel Tales do fotógrafo Peter Funch. Consideramos que embora a fotografia carregue consigo o desenvolvimento técnico em sua dialética, a contradição existente em toda e qualquer obra fotográfica não pode ser eliminada, mas deve ser reconhecida como possibilidade de superação na forma de produção do que (não)existe.
\end{abstract}

Palavras-chave: Fotografia; produção de imagens; Benjamin, W.

\section{PHOTO-GRAPHICS: REPRODUCIBILITY, TECHNIQUE AND CUTTING THE HISTORY IN WRITING IN THE EXISTING}

\begin{abstract}
The aim of this essay is to reflect on the relationship between the technical production of images and its political-social reverberations in the present. We use Walter Benjamin's ideas as a main reference, especially from the processes of technification of the art productions and the social criticism implied in these processes, in dialogue with thinkers like Vilém Flusser, Roland Barthes and Susan Sontag. As an element of theme, we will take photographs such as Lucas Landau's "Boy at Copacabana Beach on New Year's Eve" and "Memory Lane" from the Peter Funch project Babel Tales. We consider that although photography carries with it technical development in its dialectic, the contradiction existing in any and all photographic work cannot be eliminated, but it must be

${ }^{1}$ Mestranda em Psicologia - Universidade Federal do Ceará. Bolsista FUNCAP-CE. Brasileira, residente em Fortaleza - CE. E-mail: rochellyholanda@hotmail.com

${ }^{1}$ Doutorando em Psicologia - Universidade Federal do Ceará. Brasileira, residente em Fortaleza-CE. E-mail: smarcocesar@hotmail.com

${ }^{1}$ Mestrando em Psicologia - Universidade Federal do Ceará. Bolsista FUNCAP-CE. Brasileira, residente em Fortaleza - CE. E-mail: lucasamoha@gmail.com

1 Professora do ICA - Universidade Federal do Ceará. Professora da Pós-Graduação em

Psicologia. Brasileira, residente em Fortaleza-CE. E-mail: deborahantunes@ufc.br
\end{abstract}


recognized as a possibility of overcoming in the form of production of what (not) exists.

Key-words: Photograph; image production; Benjamin, $W$.

\section{Introdução}

Objetivamos nesse trabalho ensaiar algumas reflexões sobre a relação entre a produção técnica de imagens e suas reverberações político-sociais. Para tanto, utilizaremos como referencial teórico principal as ideias do pensador alemão Walter Benjamin, sobretudo no tocante aos processos de tecnificação das produções de arte e a crítica social implicada nesses processos. Em específico, trataremos da fotografia enquanto produto da técnica moderna e que tem se consolidado cada vez mais como instrumento de veiculação não só da imagem pessoal dos indivíduos, mas também da factualidade. A fotografia transpõe para o plano virtual a ordem dos acontecimentos e nela os fatos são expostos ao regime intersubjetivo. Um traço marcante desse expor e tematizar fatos através das imagens é a maleabilidade e recriação da factualidade em um novo regime de "verdade", diferenciando, assim, os fatos em si das representações e discursos sobre eles.

Como elemento de tematização tomaremos fotografias como "Menino na praia de Copacabana no réveillon em 2018" de Lucas Landau e "Memory Lane" do projeto Babel Tales do fotógrafo Peter Funch. Este projeto, em especial, reúne fotografias como documentação, mas também utiliza o recurso da manipulação das imagens dando forma representativa dos acontecimentos por meio da subjetividade do observador. A intencionalidade aqui é o elemento central do tratamento da imagem. O trabalho do fotógrafo não só expõe um parecer próprio sobre os acontecimentos e a forma da sociabilidade nos tempos atuais, mas também sugere ao observador um exercício próprio de reflexão. Como nos alertou Benjamin $(1987,194)$ contemplar as produções da era da técnica pode ser, ao mesmo tempo, pensar sobre os acontecimentos.

\footnotetext{
${ }^{1}$ Mestranda em Psicologia - Universidade Federal do Ceará. Bolsista FUNCAP-CE. Brasileira, residente em Fortaleza - CE. E-mail: rochellyholanda@hotmail.com

1 Doutorando em Psicologia - Universidade Federal do Ceará. Brasileira, residente em Fortaleza - CE. E-mail: smarcocesar@hotmail.com

${ }^{1}$ Mestrando em Psicologia - Universidade Federal do Ceará. Bolsista FUNCAP-CE. Brasileira, residente em Fortaleza - CE. E-mail: lucasamoha@gmail.com 
A fotografia ficou comumente entendida como retrato fiel das coisas, isto é, uma de suas marcas era justamente retratar o ocorrido, um enquadramento das cenas, o resgate e a perpetuação de um acontecimento. No entanto, o próprio avanço técnico que trouxe a fotografia como meio distinto de retratar fatos e pessoas modificou o modo como se produz a fotografia e como se apresenta os acontecimentos ou o modo como falamos sobre eles. Nos perguntamos sobre como uma tal "verdade dos fatos" pode ser veiculada, distorcida, manipulada ante esses novos poderes do domínio da imagem e mesmo do índice subjetivo presente no ato de fotografar.

\section{Racionalidade moderna, técnica e fotografia em Benjamin}

Em termos da pesquisa social crítica, é conveniente que os conceitos e as categorias estejam sempre em relação direta com os acontecimentos. Os conceitos não aparecem como elementos puramente abstratos ou desprovidos de um aporte empírico, mas cumprem o papel de articular o conteúdo empírico em um todo representativo de sentido que nos ajuda a compreender a ordem dos fatos (NOBRE, 2008, p. 9). Benjamin apresenta, em um projeto inicialmente recusado como trabalho de tese e que resultou no seu declínio em seguir a carreira acadêmica (FRANCO, 2015, 33), uma proposta segundo a qual a forma tradicional de conceituação compromete o saber sobre as coisas, uma vez que o conceito compreende a captura limitada do objeto. A crítica às ciências aparece, desse modo, no aspecto da colocação da verdade enquanto condição universalista e pura advinda do plano abstrato que abarca os objetos, mas que, para isso, suprime os resíduos particulares que atravessam os fenômenos (BENJAMIN, 1984, 50).

\footnotetext{
${ }^{1}$ Mestranda em Psicologia - Universidade Federal do Ceará. Bolsista FUNCAP-CE. Brasileira, residente em Fortaleza - CE. E-mail: rochellyholanda@hotmail.com

1 Doutorando em Psicologia - Universidade Federal do Ceará. Brasileira, residente em Fortaleza-CE. E-mail: smarcocesar@hotmail.com

${ }^{1}$ Mestrando em Psicologia - Universidade Federal do Ceará. Bolsista FUNCAP-CE. Brasileira, residente em Fortaleza - CE. E-mail: lucasamoha@gmail.com 
Contrário a essa postura epistemológica tradicional ${ }^{1}$, o autor propõe um modelo alegórico representativo segundo o qual ideia seria o termo que exprime a articulação entre fenômeno e sua formulação abstrata. Aqui, as ideias reúnem na forma da representação os conteúdos outrora esquecidos pela conceituação, compondo assim um todo de significado que ilustra o fenômeno. Assim,

Do mesmo modo que a mãe só começa a viver com todas as suas forças quando seus filhos, sentindo-a próxima, se agrupam em círculo em torno dela, assim também as ideias só adquirem vida quando os extremos se reúnem à sua volta. [...] Elas permanecem escuras, até que os fenômenos as reconheçam e circundem. É função dos conceitos agrupar os fenômenos, e a divisão que neles se opera graças à inteligência, com sua capacidade de estabelecer definições, é tanto mais significativa quanto tal divisão consegue de um golpe dois resultados: salvar os fenômenos e representar as ideias (BENJAMIN, 1984, 57).

O autor nos leva a crer que a teoria perde o objeto de conhecimento quando o submete a "classificações a priori que não mantém com ele qualquer relação orgânica” (BENJAMIN, 1984, 15). É preciso, pois, representar os fenômenos ligando-os com as formulações abstratas em termos de conservação das particularidades. A relação que há entre ideia e fenômeno é, por um lado, uma apropriação do conjunto de particularidades de um dado e, por outro lado, a apresentação de um fenômeno dando a ele o que Benjamin chama de “interpretação objetiva” ou "ordenamento objetivo virtual” (BENJAMIN, 1984, 15). Não se trata de negar o conceito, mas de conferir-Ihe enquanto ideia uma função de representação do fenômeno, isto é, daquilo que aparece. Pensar, portanto, não significa dar a última palavra, mas tornar representado um dado fato, conferindo a ele entendimento dentro de um plano de razoabilidade.

\footnotetext{
${ }^{1}$ No prefácio da obra "Origem do drama barroco alemão", Benjamin critica tanto os modelos indutivo e dedutivo como métodos de produção do conhecimento. Grosso modo, ambos parecem incorrer no mesmo erro da adequação do objeto ao conceito, isto é, o conceito faz subsumir o objeto.

${ }^{1}$ Mestranda em Psicologia - Universidade Federal do Ceará. Bolsista FUNCAP-CE. Brasileira, residente em Fortaleza - CE. E-mail: rochellyholanda@hotmail.com

1 Doutorando em Psicologia - Universidade Federal do Ceará. Brasileira, residente em Fortaleza-CE. E-mail: smarcocesar@hotmail.com

${ }_{1}^{1}$ Mestrando em Psicologia - Universidade Federal do Ceará. Bolsista FUNCAP-CE. Brasileira, residente em Fortaleza - CE. E-mail: lucasamoha@gmail.com

1 Professora do ICA - Universidade Federal do Ceará. Professora da Pós-Graduação em Psicologia. Brasileira, residente em Fortaleza-CE. E-mail: deborahantunes@ufc.br
} 
Trouxemos aqui um pouco das reflexões benjaminianas acerca do problema epistemológico porque elas nos conduzem a pensar sobre os modelos de interpretação dos fatos sociais. No plano da pesquisa social crítica, a análise se volta para um objeto em constante movimento e, por isso, não cabível de encapsulamento em conceitos acabados. Poderíamos falar dos contributos de Benjamin nesse âmbito de pesquisa colocando que a pesquisa social precisa sempre enunciar seus pareceres em termos transitórios e nunca em termos de permanência. O real, portanto, não é exprimível em termos de universalidade, mas sempre como contingente e contextual.

Assim ocorre com os artefatos da técnica moderna, dentre os quais nos detemos sobre a fotografia. São eles elementos em processo de transição até mesmo movida pelo próprio caráter de devir que a técnica assumiu na modernidade, diriam alguns autores (HEIDEGGER, 2007, 380). Desde o surgimento da tecnociência temos acompanhado um vertiginoso processo de acréscimo sobre as produções tecnológicas, aparecendo sempre e a cada vez artefatos e instrumentos que superam os anteriores que vão se tornando obsoletos. Parece que o fim da técnica moderna é a constante superação de seus próprios feitos.

A modernidade carrega em si, contudo, uma contradição, que marca o processo de desenvolvimento da técnica. Ao mesmo tempo que a técnica avança e traz ao homem enormes benefícios, ela mesma implica uma forma de consciência que retira do homem a sua autonomia enquanto sujeito. $\mathrm{Na}$ obra Dialética do Esclarecimento, Adorno e Horkheimer $(1985,18)$ discutem como o mito do esclarecimento, no que se refere ao progresso técnico e científico, converte-se em barbárie. Para além da racionalidade instrumental oposta ao chamado pensamento crítico reflexivo, a proeminência dos artefatos técnicos e seu alcance objetivo colocam os indivíduos ora como produtores, ora como usuários da técnica, o que resulta no empobrecimento da experiência porque

\footnotetext{
${ }^{1}$ Mestranda em Psicologia - Universidade Federal do Ceará. Bolsista FUNCAP-CE. Brasileira, residente em Fortaleza - CE. E-mail: rochellyholanda@hotmail.com

1 Doutorando em Psicologia - Universidade Federal do Ceará. Brasileira, residente em Fortaleza-CE. E-mail: smarcocesar@hotmail.com

${ }_{1}^{1}$ Mestrando em Psicologia - Universidade Federal do Ceará. Bolsista FUNCAP-CE. Brasileira, residente em Fortaleza - CE. E-mail: lucasamoha@gmail.com 
cria um véu que encobre as condições objetivas da sociedade capitalista e amortece a crítica.

A experiência na era da técnica é uma "experiência artificial", tal como seus artefatos, uma vez perdida a espontaneidade e a clareza do que se vive. Para utilizar o vocabulário benjaminiano, seria especialmente uma vivência (Erlebnis) em contraposição à experiência (Erfährung), na medida em que, como o autor nos coloca em "Experiência e pobreza" (BENJAMIN, 1987, 114), o que ocorre é exatamente a retração, a decadência da experiência em meio a uma crise da transmissão, da possibilidade de uma continuidade do saber e da memória. Analisar um produto tecnológico é, portanto, pensar seu processo de aparecimento e desenvolvimento em constante ligação com o mundo dos fatos e acontecimentos, sobretudo no tocante ao que sua presença acarreta para o nível das relações intersubjetivas e subjetivas.

No tocante à fotografia enquanto produto técnico, Benjamin nos afirma no ensaio "Pequena história da fotografia" que o daguerreótipo ${ }^{2}$ marca 0 momento áureo da fotografia justamente pelo fato de que esse processo resultava em peças únicas, conservando o hic et nunc da obra, a aura do objeto produzido (BENJAMIN, 1987, 169). Sem possibilidade de reprodução, a peça era "uma figura singular, composta de elementos espaciais e temporais: a aparição única de uma coisa distante, por mais próxima que ela esteja" (BENJAMIN, 1987, 101). O processo do daguerreótipo, diferentemente daquele da câmera escura, trazia à tona uma imagem menos carregada de subjetividade porque o retrato não era feito pela mão e sim produzido pela pictoriedade do próprio artefato. O que Benjamin considera como o apogeu da fotografia é, portanto, sua fase pré-industrial e ainda não reprodutível.

\footnotetext{
2 Daguerréotype (francês), aparelho fotográfico primitivo, inventado por Louis Jacques Daguerre (1787-1851).

${ }^{1}$ Mestranda em Psicologia - Universidade Federal do Ceará. Bolsista FUNCAP-CE. Brasileira, residente em Fortaleza - CE. E-mail: rochellyholanda@hotmail.com

${ }^{1}$ Doutorando em Psicologia - Universidade Federal do Ceará. Brasileira, residente em Fortaleza-CE. E-mail: smarcocesar@hotmail.com

${ }_{1}^{1}$ Mestrando em Psicologia - Universidade Federal do Ceará. Bolsista FUNCAP-CE. Brasileira, residente em Fortaleza - CE. E-mail: lucasamoha@gmail.com 
A fotografia ocupa nesse sentido uma dupla funcionalidade, por um lado ela aparece como produto artístico - segundo Benjamin, um dos primeiros artefatos artísticos produzidos mediante a técnica moderna -, por outro lado ela aparece como instrumento documental pela função de retrato. Com efeito, a câmera surgiu como o "aparelho que podia rapidamente gerar uma imagem do mundo visível, com um aspecto tão vivo e tão verídico como a própria natureza" (BENJAMIN, 1987, 95). Captar o mundo pela via da câmera era ao mesmo tempo transpô-lo para uma representação fidedigna e essa representação era também uma obra que em si carregava os elementos puros consoantes à aura da obra de arte.

Um instante no tempo, um fato, um acontecimento, o aqui e agora, passível ou não de comunicação, eram preservados na representação fotográfica porque ainda não havia a reprodução técnica em massa. Sobre isso salienta Benjamin:

As primeiras pessoas reproduzidas estavam nas fotos sem que nada se soubesse sobre sua vida passada, sem nenhum texto escrito que as identificasse. Os jornais ainda eram artigos de luxo, raramente comprados, e lidos no café, a fotografia ainda não tinha tornado seu instrumento, e pouquíssimos homens viam seu nome impresso. $O$ rosto humano era rodeado por um silêncio em que o olhar repousava. Em suma, todas as possibilidades da arte do retrato se fundam no fato de que não se estabelecera ainda um contato entre a atualidade e a fotografia (BENJAMIN, 1987, 95).

Benjamim nos explica que a fotografia não possuía ainda o emprego jornalístico de ilustração da informação. A informação contida na fotografia pertencia exclusivamente a ela mesma e sua função artística era a contemplação estética e seus efeitos. O caráter documental da fotografia tinha a ver com aquilo que ela por si retratava e não alhures e esse aspecto se mostra anteriormente ao momento da reprodutibilidade técnica da arte.

Ao comentar o trabalho fotográfico de August Sander, Benjamin assevera que o fotógrafo "partiu simplesmente da observação imediata, isenta de preconceitos" e que, justamente nisso "existe uma terna empiria que se

${ }_{1}^{1}$ Mestranda em Psicologia - Universidade Federal do Ceará. Bolsista FUNCAP-CE. Brasileira, residente em Fortaleza - CE. E-mail: rochellyholanda@hotmail.com

${ }^{1}$ Doutorando em Psicologia - Universidade Federal do Ceará. Brasileira, residente em Fortaleza-CE. E-mail: smarcocesar@hotmail.com

${ }_{1}^{1}$ Mestrando em Psicologia - Universidade Federal do Ceará. Bolsista FUNCAP-CE. Brasileira, residente em Fortaleza - CE. E-mail: lucasamoha@gmail.com

${ }^{1}$ Professora do ICA - Universidade Federal do Ceará. Professora da Pós-Graduação em Psicologia. Brasileira, residente em Fortaleza-CE. E-mail: deborahantunes@ufc.br 
identifica intimamente com o objeto e com isso transforma-se em teoria" (BENJAMIN, 1987, 103). Essa reflexão nos sugere que a tentativa de preservar a aura na fotografia significa permitir que seu conteúdo apareça isento, resultante, portanto, da experiência única do observador fotógrafo. A obra aqui é, assim, também única e retrata essa mesma experiência estética. A estética é uma maneira pela qual o real é posto em evidência.

Como dito anteriormente, averiguar um objeto da cultura do ponto de vista do exame científico significa perceber as modificações pertinentes de seu devir. O transcurso de um artefato cultural carrega em si as marcas do social, ou seja, as transformações que esse artefato sofre têm a ver com a função que a ele é atribuída. Ao mesmo tempo, podemos dizer que, por essa mesma razão, a história de um dado artefato é também um documento do social, uma amostra que traz à tona a ordem da factualidade e nos ajuda a entender a dinâmica da própria vida humana em diferentes momentos.

Isso posto, falaremos sobre a principal mudança na fotografia, qual seja, a sua reprodutibilidade. Para Benjamin, "o maior perigo da fotografia contemporânea" (BENJAMIN, 1987, 105) é a comercialização. Nesse sentido, a fotografia se torna objeto subserviente ao capital e se coloca como artefato de fetiche, como qualquer outra mercadoria. As reproduções fotográficas de obras de arte são comercializadas em massa, o que acarreta, por um lado, a divulgação e o alcance de maior número de observadores, mas, por outro lado, incorre na perda da aura da obra retratada. O retrato não é mais único e singular. Assim, vejamos o que diz Benjamin sobre a nova forma da fotografia na era da reprodutibilidade técnica:

Nela se desmascara a atitude de uma fotografia capaz de realizar infinitas montagens com uma luta de conversas, mas incapaz de compreender um único dos contextos humanos em que ela aparece. Essa fotografia está mais a serviço do valor de venda de suas criações, por mais oníricas que sejam, que a serviço do conhecimento. Mas se a verdadeira face dessa "criatividade" fotográfica é o reclame ou a associação, sua contrapartida legítima é o desmascaramento ou a construção (BENJAMIN, 1987, 106).

${ }_{1}^{1}$ Mestranda em Psicologia - Universidade Federal do Ceará. Bolsista FUNCAP-CE. Brasileira, residente em Fortaleza - CE. E-mail: rochellyholanda@hotmail.com

${ }^{1}$ Doutorando em Psicologia - Universidade Federal do Ceará. Brasileira, residente em Fortaleza-CE. E-mail: smarcocesar@hotmail.com

${ }_{1}^{1}$ Mestrando em Psicologia - Universidade Federal do Ceará. Bolsista FUNCAP-CE. Brasileira, residente em Fortaleza - CE. E-mail: lucasamoha@gmail.com

${ }^{1}$ Professora do ICA - Universidade Federal do Ceará. Professora da Pós-Graduação em Psicologia. Brasileira, residente em Fortaleza-CE. E-mail: deborahantunes@ufc.br 
A fotografia pode servir não mais como objeto de contemplação, mas de comunicação de algo previamente pensado. Ela pode gerar efeitos antecipados por meio do reclame, da publicidade e de propaganda. Assim também a fotografia pode servir para o mascaramento dos fatos. Seu emprego pode resultar na comunicação distorcida mediante a montagem e a reconstrução dos fatos. Portanto, ligada ao fetiche da mercadoria a fotografia serve à venda e, como instrumento documental, pode servir ao retrato montado e distorcido das ocorrências colaborando com o empobrecimento da experiência

Entretanto, Benjamin nos chama atenção para o fato de que, ainda que seja nessas condições, a forma que a fotografia assume nessa era da técnica mostrará ao observador mais atento, numa visão de conjunto, a marca da nossa época. Isso significa que os traços marcantes do modelo de fotografia que temos e o seu emprego nos dizem em que tempos vivemos, nos servem como objeto de compreensão de nossa temporalidade e de nosso contexto social.

\section{Entre Benjamin, Barthes, Flusser e Sontag: técnica e fotografia na atualidade}

Em 1988, com o slogan "Carregue no botão que nós fazemos o resto", a Kodak colocou na mão dos consumidores de todo o mundo a primeira máquina fotográfica de fácil acesso e uso. A nova câmera podia ser transportada para qualquer lugar com facilidade. Era pré-carregada com filme suficiente para cem poses. O processo árduo e meticuloso até então converteu-se em algo simples e esse foi o intuito de George Eastman. A Eastman Kodak Company foi fundada por George Eastman, o inventor do filme fotográfico em 1888 e é hoje uma empresa multinacional dedicada ao design, produção e comercialização de equipamentos fotográficos profissionais e amadores. Ao longo dos anos o

\footnotetext{
${ }^{1}$ Mestranda em Psicologia - Universidade Federal do Ceará. Bolsista FUNCAP-CE. Brasileira, residente em Fortaleza - CE. E-mail: rochellyholanda@hotmail.com

${ }^{1}$ Doutorando em Psicologia - Universidade Federal do Ceará. Brasileira, residente em Fortaleza - CE. E-mail: smarcocesar@hotmail.com

${ }^{1}$ Mestrando em Psicologia - Universidade Federal do Ceará. Bolsista FUNCAP-CE. Brasileira, residente em Fortaleza - CE. E-mail: lucasamoha@gmail.com 
empreendimento tornou-se pioneiro com uma infinidade de produtos e processos inovadores que tornaram a fotografia mais simples. ${ }^{3}$

A Kodak tornou-se famosa pela grande publicização dos seus produtos que tornaram acessível o fotografar, entretanto não conseguiu se reinventar mediante as transformações tecnológicas que inovaram modos de capturar a realidade sucumbindo então ao advento de câmeras digitais, o que tornou sua produção obsoleta. A empresa que já deteve pelo menos $90 \%$ do filme fotográfico usado nos E.U.A. sucumbiu à nostalgia enquanto o mercado se adaptou as novas mídias. Agora figuram no cotidiano aparatos tecnológicos ainda mais acessíveis, todavia o recorte dado pelo obturador de uma câmera não necessariamente compõe a própria realidade. ${ }^{4}$

Nos escritos de Roland Barthes, A câmara clara: Nota sobre a fotografia, o autor acredita que "[...] o que a fotografia reproduz ao infinito só ocorreu uma vez: ela repete mecanicamente 0 que nunca mais poderá repetir-se existencialmente" (BARTHES, 1984, 13). A tecnologia e o aperfeiçoamento da câmera fotográfica fizeram da fotografia algo acessível e compartilhada por todos. Entretanto, o processo de registrar mecanicamente uma imagem em condições iguais ao olho humano em um determinado momento trouxe outras proporções. A tecnificação vai caracterizar a fotografia. A priori, ela pode representar a visão do sujeito frente a um objeto em vista, mas não apenas isso.

Para Barthes (1984, 20-21), a fotografia está no entrecruzamento de dois processos: um de ordem química, sobre a ação da luz sobre certas substâncias; e outro de ordem física e que diz da formação da imagem através do dispositivo óptico. Acrescenta ainda que uma foto pode ser objeto de três práticas (ou três

\footnotetext{
${ }^{3}$ História sobre a Kodak: das chapas de vidro às imagens digitais KODAK. Disponível em: <http://wwwpt.kodak.com/PT/pt/corp/1030.shtml> Acesso em: 04 março 2019.

${ }^{4}$ Kodak: Como a era digital se voltou contra um de seus criadores. Disponível em: $<$ https://www.terra.com.br/noticias/tecnologia/negocios-e-ti/kodak-como-a-era-digital-se-voltoucontra-um-de-seus-criadores, 19382feb711ea310VgnCLD200000bbcceb0aRCRD.html> Acesso em 03 março 2019.

${ }^{1}$ Mestranda em Psicologia - Universidade Federal do Ceará. Bolsista FUNCAP-CE. Brasileira, residente em Fortaleza - CE. E-mail: rochellyholanda@hotmail.com

${ }^{1}$ Doutorando em Psicologia - Universidade Federal do Ceará. Brasileira, residente em Fortaleza - CE. E-mail: smarcocesar@hotmail.com

${ }^{1}$ Mestrando em Psicologia - Universidade Federal do Ceará. Bolsista FUNCAP-CE. Brasileira, residente em Fortaleza - CE. E-mail: lucasamoha@gmail.com

1 Professora do ICA - Universidade Federal do Ceará. Professora da Pós-Graduação em Psicologia. Brasileira, residente em Fortaleza-CE. E-mail: deborahantunes@ufc.br
} 
emoções): fazer, suportar, olhar. Nessa perspectiva o autor remete a três elementos a composição fotográfica: ooperator (fotógrafo); o spectator, que somos todos nós que compulsamos álbuns, arquivos e coleções de fotos; e, por fim, aquele que é fotografado, o alvo, o spectrum da fotografia. O autor escolhe essa denominação justificando-a pela relação com o espetáculo e a coisa terrível que há em toda fotografia: "o retorno do morto".

Barthes $(1984,23)$ afirma ainda que o que caracteriza as sociedades ditas avançadas é que estas consomem imagens e não crenças, como as do passado; são mais liberais, mas também mais "falsas" - coisa que é traduzida na consciência, como se a imagem universalizada, produzisse um mundo sem diferenças (indiferente). O autor complementa considerando que a fotografia pode ser resquício de loucura ou sensatez. Sensata desde que seu realismo seja relativo, louca quando seu realismo é absoluto. Essas duas vias oferecem a escolha ao espectador que deseja submeter-se ao código civilizado das ilusões recortadas ou o afronte do despertar intratável da realidade.

Assim, as imagens fotográficas, como observa Flusser (1985,7), são códigos que traduzem eventos em situações, processos em cenas. Não é que as imagens tornem eternos eventos, elas substituem eventos por cenas e tal poder, inerente à estruturação plena da imagem, domina a dialética interna da própria fotografia, própria a toda mediação e nela se manifesta de maneira única. Tais imagens são mediações entre sujeitos e o mundo, visto que este último não é acessível imediatamente. O propósito das imagens é, portanto, representá-lo, mas ao fazê-lo entrepõem-se entre eles: "o homem ao invés de se servir das imagens em função do mundo, passa a viver em função de imagens".

A fim de reunir contribuições para a compreensão dos processos comunicativos na contemporaneidade, mapeiam-se brevemente as concepções sobre comunicação de Vilém Flusser. O filósofo que é um dos pioneiros ao estudar "comunicologia", ciência da mídia e comunicação no Brasil, criou o primeiro curso da área no país na década de 1960. Nascido em Praga

${ }^{1}$ Mestranda em Psicologia - Universidade Federal do Ceará. Bolsista FUNCAP-CE. Brasileira, residente em Fortaleza - CE. E-mail: rochellyholanda@hotmail.com

${ }^{1}$ Doutorando em Psicologia - Universidade Federal do Ceará. Brasileira, residente em Fortaleza-CE. E-mail: smarcocesar@hotmail.com

${ }_{1}^{1}$ Mestrando em Psicologia - Universidade Federal do Ceará. Bolsista FUNCAP-CE. Brasileira, residente em Fortaleza - CE. E-mail: lucasamoha@gmail.com 
(Tchecoslováquia) em 1920, Flusser fugiu do nazismo em 1939, sendo o único membro de sua família a sobreviver ao Holocausto e chegando ao Brasil em 1940. Para os estudos do autor o ser humano é na verdade um animal simbolicum. Este é o elemento central de sua obra, visto que a humanidade tem como necessidade fundamental se comunicar, considerando inclusive as mídias que orbitam ao seu redor e atentando à relação entre os homens e objetos (HANKE, 2004, 60).

A obra Filosofia da caixa preta: ensaios para uma futura filosofia da fotografia ${ }^{5}$ elenca parte das contribuições de Flusser nos estudos sobre os meios de comunicação e da cultura do século XX. Nesse trabalho o pensador elabora reflexões sobre o fenômeno fotográfico no qual desenvolve uma análise singular da sociedade "pós-histórica" - em que a onipresença das imagens mediadas pela tecnologia se sobressai sobre os conceitos próprios à sociedade industrializada. Em seus ensaios, o autor trabalha com a hipótese segundo a qual observa duas revoluções fundamentais na estrutura cultural. A primeira seria a invenção da escrita linear, em que inaugura a História como tal, e uma segunda, denominada por ele como a invenção das imagens técnicas. A esta última o autor atribui o surgimento de um modus operandi particularmente difícil de definir até então (FLUSSER, 1985, 4).

Flusser $(1985,26)$ acredita que o que distingue a fotografia das demais imagens tecnificadas se revela ao considerarmos como são distribuídas. As fotografias, para o autor, são superfícies imóveis e mudas e que esperam ser multiplicadas ao infinito e, tal qual folhas de papel, podem ser guardadas em gavetas sem maiores exigências para seu armazenamento. ${ }^{6}$

\footnotetext{
${ }^{5}$ Nesta obra, são resumidas conferências pronunciadas por Vilém Flusser na França e na Alemanha que, a pedido da EuropeanPhotography, foram reunidas no livro publicado primeiramente em alemão no ano de 1983.

${ }^{6}$ Ressalta-se que a obra foi escrita em período anterior à ascensão das tecnologias que permitem a massificação da distribuição de imagens no âmbito digital.

${ }_{1}^{1}$ Mestranda em Psicologia - Universidade Federal do Ceará. Bolsista FUNCAP-CE. Brasileira, residente em Fortaleza - CE. E-mail: rochellyholanda@hotmail.com

${ }^{1}$ Doutorando em Psicologia - Universidade Federal do Ceará. Brasileira, residente em Fortaleza - CE. E-mail: smarcocesar@hotmail.com

${ }^{1}$ Mestrando em Psicologia - Universidade Federal do Ceará. Bolsista FUNCAP-CE. Brasileira, residente em Fortaleza - CE. E-mail: lucasamoha@gmail.com

${ }^{1}$ Professora do ICA - Universidade Federal do Ceará. Professora da Pós-Graduação em Psicologia. Brasileira, residente em Fortaleza-CE. E-mail: deborahantunes@ufc.br
} 
Em sua elaboração a respeito das imagens na contemporaneidade, no livro Pós-História: Vinte instantâneos e um modo de usar, Flusser $(2011,113)$ atenta às mudanças físicas sofridas no mundo, atestando que somos envoltos agora por cores e superfícies que remetem a filmes, fotografias, programas de TV resplandecentes em tecnicolor. Tal transformação não é delimitada apenas esteticamente: tantas superfícies nos cercam em cor sobretudo porque irradiam mensagens que informam a respeito do mundo. Agora são as superfícies e não mais as linhas textuais que codificam o mundo; seja por fotografias, seja telas de cinema que subvertem a ordem existente outrora, as imagens se tornaram a media dominante.

Por meio das discussões elaboradas até aqui, tomamos como objeto de análise fotografias que provocam dissonâncias entre superfícies imagéticas e as linhas textuais de suas histórias. A escolha das imagens é acompanhada de traços técnicos que marcam a contemporaneidade, desde o aparato fotográfico inserido entre o sujeito responsável pela sua construção (seja a máquina fotográfica ou softwares de edição) e o mundo, o acesso disponibilizado via redes sociais/internet e a maneira que os espectadores entram em contato com o conteúdo das obras.

O ano de dois mil e dezoito, no Brasil, começou com o fervor dos compartilhamentos em redes sociais virtuais e interpretações a respeito da fotografia abaixo. Um menino, aparentemente sozinho, sem camisa e avançando no mar de Copacabana assistia à queima de fogos na orla carioca. Em segundo plano, observamos um outro mar, uma multidão branca de pessoas brancas que tira selfies na chegada do ano novo. Por dias ecoaram nas mídias sociais críticas e especulações em torno da fotografia, pouco importava sobre a identidade do menino na imagem, mas sim a suposta narrativa que atravessava sentidos dados por espectadores no presente do momento capturado.

\section{Fotografia 1 - Menino na praia de Copacabana no réveillon em 2018}

${ }^{1}$ Mestranda em Psicologia - Universidade Federal do Ceará. Bolsista FUNCAP-CE. Brasileira, residente em Fortaleza - CE. E-mail: rochellyholanda@hotmail.com

${ }^{1}$ Doutorando em Psicologia - Universidade Federal do Ceará. Brasileira, residente em Fortaleza - CE. E-mail: smarcocesar@hotmail.com

${ }^{1}$ Mestrando em Psicologia - Universidade Federal do Ceará. Bolsista FUNCAP-CE. Brasileira, residente em Fortaleza - CE. E-mail: lucasamoha@gmail.com 


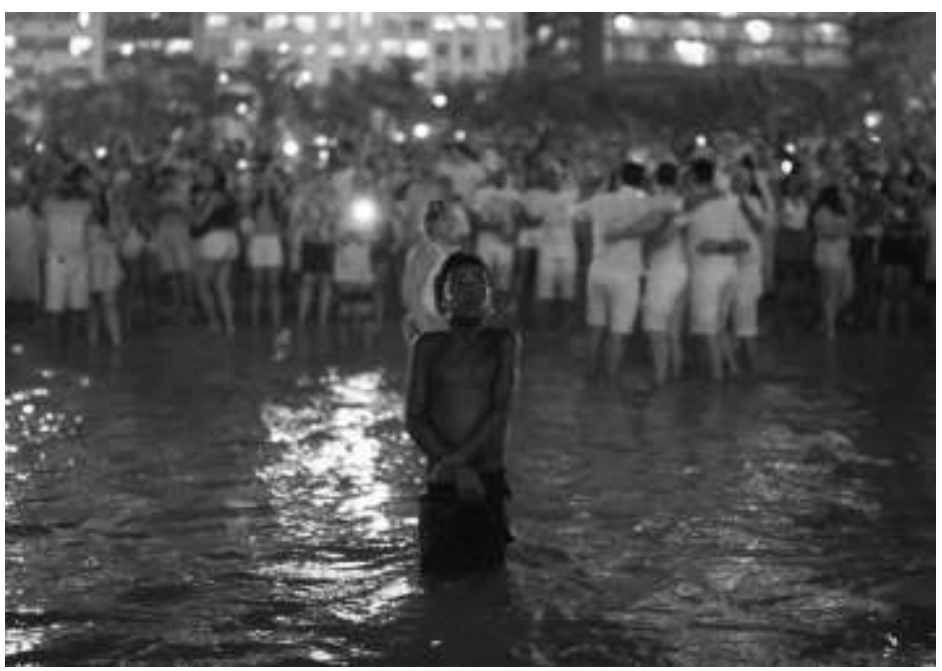

Fonte: Landau (2018) - Reprodução Facebook. ${ }^{7}$

Após a repercussão da foto, considerada um dos registros mais marcantes do réveillon, o fotógrafo responsável, Lucas Landau, publicou em sua página pessoal no Facebook o interesse de conhecer o garoto. A publicação ultrapassou os oito mil compartilhamentos e as 33 mil reações, alavancando discussões em torno das possíveis narrativas sobre o menino que protagonizou o registro. As interpretações vão desde a (in)visibilidade de uma criança negra extasiada na contemplação de um céu iluminado até as reflexões socioeconômicas de quem associou a imagem ao contraste sócio racial com a multidão branca atrás da criança. Não nos aprofundaremos no confronto dessas histórias, mas sim na fotografia e em sua relação com a ficção.

A criança que protagonizou o registro viral no primeiro dia do ano acompanhava a mãe, vendedora ambulante que trabalhava durante a festa de ano novo. Quando o show pirotécnico começou, o menino se afastou da mãe para admirar, em seu momento particular, a beleza do céu que o rodeava. Outro ponto a ser considerado é que o fotógrafo tirou duas fotos do momento e as duas

7 LANDAU, Lucas. Copacabana, 2018. [2018] 1 fotografia, color. Disponível em: $<$ https://www.facebook.com/photo.php?fbid=10215003728068814\&set=pb.1297914732.2207520000.1561066787.\&type=3\&theater $>$ Acesso em: 04 março 2019.

1 Mestranda em Psicologia - Universidade Federal do Ceará. Bolsista FUNCAP-CE. Brasileira, residente em Fortaleza - CE. E-mail: rochellyholanda@hotmail.com

${ }^{1}$ Doutorando em Psicologia - Universidade Federal do Ceará. Brasileira, residente em Fortaleza-CE. E-mail: smarcocesar@hotmail.com

${ }_{1}^{1}$ Mestrando em Psicologia - Universidade Federal do Ceará. Bolsista FUNCAP-CE. Brasileira, residente em Fortaleza - CE. E-mail: lucasamoha@gmail.com

${ }^{1}$ Professora do ICA - Universidade Federal do Ceará. Professora da Pós-Graduação em Psicologia. Brasileira, residente em Fortaleza-CE. E-mail: deborahantunes@ufc.br 
foram publicadas: a primeira, já apresentada, e de outro ponto de vista a segunda (Fotografia 2), em que o mesmo menino aparece de costas para a praia contemplando sozinho o céu. Apenas a primeira teve repercussão significativa nas redes.

\section{Fotografia 2 - Menino na praia de Copacabana no réveillon em 2018}

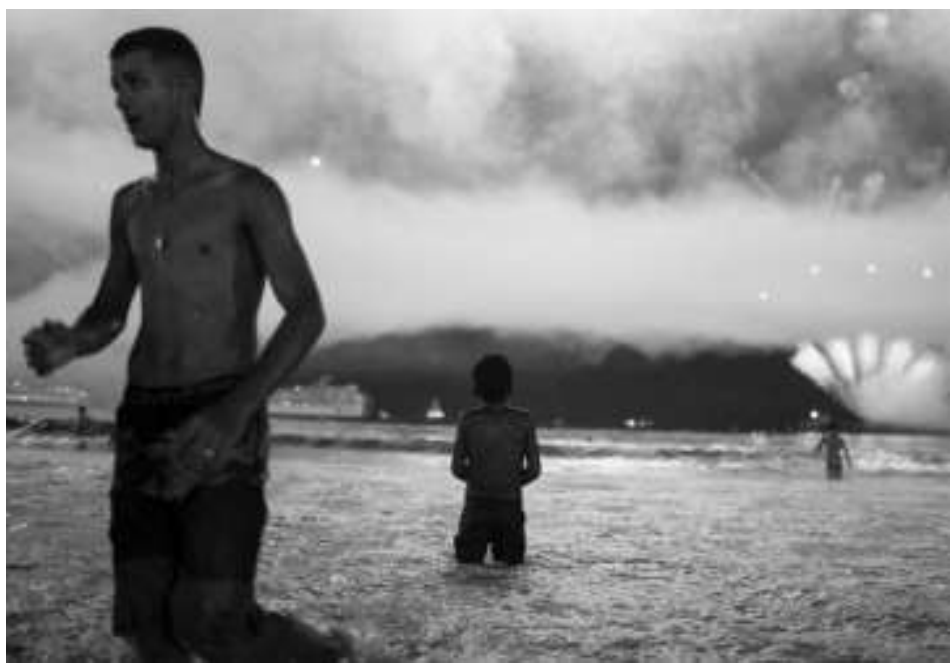

Fonte: Lucas Landau (2018) - Reprodução Facebook. ${ }^{8}$

Em História e Psicanálise: entre ciência e ficção, são reunidos alguns textos nos quais Michel de Certeau propõe reflexões sobre o fazer historiográfico em diálogo com o saber psicanalítico, bem como a relação entre história e ficção. As travessias subjetivas percorridas nos escritos do autor abrem possibilidades para se pensar o conhecimento histórico (ORELLANA, 2012, 9). Segundo Certeau $(2016,60)$, a encenação admissível de produção de um efeito real estaria ligada ao fazer historiográfico. No entanto, o real apresentado faz ocultar, por trás da figura de passado, o sistema social e técnico que a produz. A foto do

8LANDAU, Lucas. Copacabana, 2018. [2018] 1 fotografia, color. Disponível em: $<$ https://www.facebook.com/photo.php?fbid=10215003727628803\&set=pb.1297914732.2207520000.1561066787.\&type=3\&theater > Acesso em: 04 março 2019.

1 Mestranda em Psicologia - Universidade Federal do Ceará. Bolsista FUNCAP-CE. Brasileira, residente em Fortaleza - CE. E-mail: rochellyholanda@hotmail.com

${ }^{1}$ Doutorando em Psicologia - Universidade Federal do Ceará. Brasileira, residente em Fortaleza-CE. E-mail: smarcocesar@hotmail.com

${ }^{1}$ Mestrando em Psicologia - Universidade Federal do Ceará. Bolsista FUNCAP-CE. Brasileira, residente em Fortaleza - CE. E-mail: lucasamoha@gmail.com

${ }^{1}$ Professora do ICA - Universidade Federal do Ceará. Professora da Pós-Graduação em Psicologia. Brasileira, residente em Fortaleza-CE. E-mail: deborahantunes@ufc.br 
menino no réveillon não diz da história do menino, mas de nós e de nossas projeções, sobre a indignação com o que achamos que a imagem mostra.

Para Flusser $(1985,7)$, as imagens são superfícies que intentam representações do mundo, geralmente de algo que se encontra fora no espaço e no tempo. Portanto, são também resultado do esforço de se abstrair duas das quatro dimensões espaço-temporais, a fim de que sejam conservadas apenas as dimensões do plano. Elas devem creditar sua origem à capacidade de abstração específica, à imaginação. Entretanto existem dois aspectos desse processo: se, de um lado, duas dimensões são abstraídas; de outro, é permitido reconstituir as duas dimensões abstraídas na imagem. Ou seja, a imaginação é a capacidade de fabricar e decifrar imagens.

Nas inferências coletivas e/ou particulares há um elemento projetivo que atravessa discursos e faz com que as imagens figurem em um cenário de configuração social para além da intencionalidade do fotógrafo ao realizar seu trabalho. Para Benjamin,

Apesar de toda a perícia do fotógrafo e de tudo o que existe de planejado em seu comportamento, o observador sente a necessidade irresistível de procurar nessa imagem a pequena centelha do acaso, do aqui e agora, com a qual a realidade chamuscou a imagem, de procurar o lugar imperceptível em que o futuro se aninha ainda hoje em minutos únicos, há muito extintos, e com tanta eloquência que podemos descobri-lo olhando para trás. A natureza que fala a câmera não é a mesma que fala ao olhar; é outra, especialmente porque substitui a um espaço que ele percorre trabalhando conscientemente pelo homem, um espaço que ele percorre inconscientemente. Percebemos, em geral, o movimento de um homem que caminha, ainda que em grandes traços, mas nada percebemos de sua atitude na exata fração de segundo em que ele dá um passo. A fotografia mostra essa atitude, através dos seus recursos auxiliares: câmera lenta, ampliação. Só a fotografia revela esse inconsciente ótico, como só a psicanálise revela o inconsciente pulsional (BENJAMIN, 1987, 94).

Por meio do conceito de inconsciente ótico, Benjamin (1987, 94) compara a máquina fotográfica a um bisturi que recorta o real. O obturador da câmera captura algo capaz de revelar ao espectador algo que diz da sua própria consciência no espaço das representações. O aparato fotográfico outrora era responsável pela "revelação" da imagem recortada e só a posteriori colocá-la

${ }_{1}^{1}$ Mestranda em Psicologia - Universidade Federal do Ceará. Bolsista FUNCAP-CE. Brasileira, residente em Fortaleza - CE. E-mail: rochellyholanda@hotmail.com

${ }^{1}$ Doutorando em Psicologia - Universidade Federal do Ceará. Brasileira, residente em Fortaleza-CE. E-mail: smarcocesar@hotmail.com

${ }_{1}^{1}$ Mestrando em Psicologia - Universidade Federal do Ceará. Bolsista FUNCAP-CE. Brasileira, residente em Fortaleza - CE. E-mail: lucasamoha@gmail.com

${ }^{1}$ Professora do ICA - Universidade Federal do Ceará. Professora da Pós-Graduação em Psicologia. Brasileira, residente em Fortaleza-CE. E-mail: deborahantunes@ufc.br 
diante dos olhos e apresentar sua representação do mundo. Agora o processo é ainda mais simples e a imagem é capturada, revelada e compartilhada imediatamente. Aqui surge ainda um novo elemento, a imediaticidade da percepção à imagem.

A afinidade entre o pensamento de Benjamin e a psicanálise aparece nesse conceito quando o filósofo reconhece o movimento do inconsciente, mobilizando um elemento da memória como produto de uma experiência vivida anteriormente pelo sujeito que, ao contemplar uma imagem, torna-se consciente atribuindo a ela um sentido particular a essa representação. $O$ hic et nunc do original constitui o conteúdo da sua autenticidade e a esfera da autenticidade escapa à reprodutibilidade técnica e não apenas à técnica. A reprodução técnica é mais autônoma que a reprodução manual: por meio da fotografia podem ser acentuados aspectos do original acessíveis ao obturador, ajustável e com o poder de seleção arbitrária do ângulo de observação, mas inacessíveis ao olho humano. Permite ainda, graças a recursos como câmera lenta, fixar imagens que fogem à ótica natural e, principalmente, pode aproximar a obra do indivíduo (BENJAMIN, 1987, 174).

Para além de reflexões sobre a fotografia ou o cinema, as proposições benjaminianas sobre a reprodutibilidade técnica expõem ainda que tal processo possui uma natureza esteticamente fascista, visto que se coloca de modo tendencioso como meio de expressão das massas, uma "estetização da política" (FRANCO, 2014, 339).

Considerando a fotografia enquanto documento histórico e sua pretensão de realidade, bem como os desencontros entre o ficcional e o científico, Certeau (2016, 62) descreve a ficção, em suas diferentes modalidades, como o discurso que dá forma ao real, apesar de que ela própria não tenha a intenção de representá-lo. Embora o discurso histórico tenha o desejo pelo efeito do real, não concede uma verdade sobre o passado. Partindo

\footnotetext{
${ }^{1}$ Mestranda em Psicologia - Universidade Federal do Ceará. Bolsista FUNCAP-CE. Brasileira, residente em Fortaleza - CE. E-mail: rochellyholanda@hotmail.com

1 Doutorando em Psicologia - Universidade Federal do Ceará. Brasileira, residente em Fortaleza - CE. E-mail: smarcocesar@hotmail.com

${ }^{1}$ Mestrando em Psicologia - Universidade Federal do Ceará. Bolsista FUNCAP-CE. Brasileira, residente em Fortaleza - CE. E-mail: lucasamoha@gmail.com 
das discussões em torno da produção da história, o lugar da narrativa surge como entremeio entre ciência e ficção

[...] essa ficção-científica funciona, à semelhança de outras heterologias, no ponto de junção entre discurso científico e linguagem ordinária, exatamente no ponto em que o passado se conjuga com 0 presente e em que as indagações sem tratamento técnico retornam como metáforas narrativas (CERTEAU, 2016, 63).

Tais reflexões sobre o caráter ficcional e inventivo presente na fotografia podem ser elaboradas, por exemplo, a partir de percepções provocadas por meio de projetos fotográficos como Babel Tales (2007), do fotógrafo dinamarquês Peter Funch.

Fotografia 3 - Fotografia Memory Lane no projeto Babel Tales do fotógrafo Peter Funch.

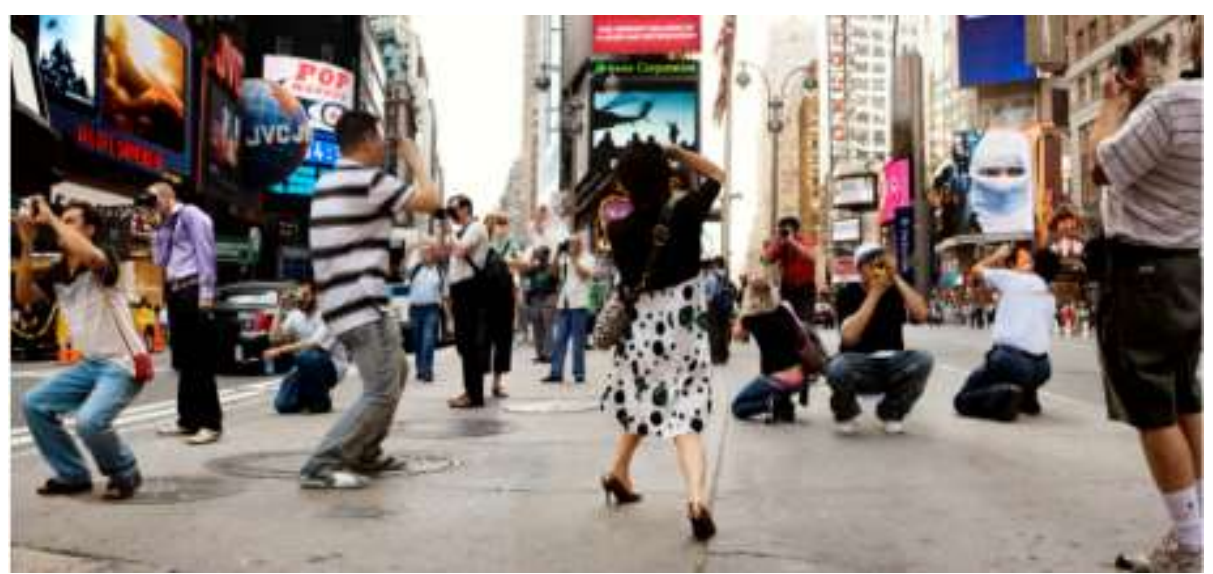

${ }_{1}^{1}$ Mestranda em Psicologia - Universidade Federal do Ceará. Bolsista FUNCAP-CE. Brasileira, residente em Fortaleza - CE. E-mail: rochellyholanda@hotmail.com

${ }^{1}$ Doutorando em Psicologia - Universidade Federal do Ceará. Brasileira, residente em Fortaleza-CE. E-mail: smarcocesar@hotmail.com

${ }^{1}$ Mestrando em Psicologia - Universidade Federal do Ceará. Bolsista FUNCAP-CE. Brasileira, residente em Fortaleza - CE. E-mail: lucasamoha@gmail.com

${ }^{1}$ Professora do ICA - Universidade Federal do Ceará. Professora da Pós-Graduação em Psicologia. Brasileira, residente em Fortaleza-CE. E-mail: deborahantunes@ufc.br 
Fonte: Peter Funch (2007) - Reprodução online. ${ }^{9}$

Em um primeiro olhar a foto acima provoca curiosidade sobre o que tantas pessoas poderiam estar fotografando ao mesmo tempo. No entanto há um mistério aqui. Essa imagem faz parte de um trabalho intitulado Babel Tales, projeto do fotógrafo Peter Funch (2007), que une fotografia documental e fotografia manipulada explorando as relações humanas, bem como sua ausência, nas grandes cidades contemporâneas. Seus trabalhos são documentos de momentos que nunca existiram, pois são composições sobrepostas de centenas de momentos capturados durante um período em que o fotógrafo tirou fotos na mesma posição. Ao sobrepor as imagens, cria um trabalho fictício baseado na fotografia documental e levanta questões acerca da realidade contra ficção, desafiando nossa noção de fotografia como sendo uma representação de um determinado momento no tempo.

Por definição, fotografia é arte ou processo de fixar a imagem de qualquer objeto ou realidade através de sensor digital ou superfície fotossensível (película ou chapa) com o auxílio da luz. No entanto, as fotografias são também atravessamentos de sentidos atribuídos por espectadores que projetam através de suas interpretações, particularidades que não necessariamente dizem respeito do traço de realidade capturado.

Retornando ao exemplo citado anteriormente, a imagem que viralizou no país no primeiro dia do ano não conta a história do momento na qual foi tirada, há algo que escapa à lente da câmera e as interpretações que se sucederam. Berger $(2017,90)$ afirma que, entre o momento registrado e o momento presente em que se olha para a fotografia, existe um abismo. Embora a fotografia detenha em si um fluxo do tempo no qual o evento fotografado

9 FUNCH, Peter. Babel Tales (2007). Projeto fotográfico, color. Disponível em:< https://www.designboom.com/art/peter-funch-babel-tales/> Acesso em 05 março 2019.

${ }_{1}^{1}$ Mestranda em Psicologia - Universidade Federal do Ceará. Bolsista FUNCAP-CE. Brasileira, residente em Fortaleza - CE. E-mail: rochellyholanda@hotmail.com

${ }^{1}$ Doutorando em Psicologia - Universidade Federal do Ceará. Brasileira, residente em Fortaleza - CE. E-mail: smarcocesar@hotmail.com

${ }^{1}$ Mestrando em Psicologia - Universidade Federal do Ceará. Bolsista FUNCAP-CE. Brasileira, residente em Fortaleza - CE. E-mail: lucasamoha@gmail.com

${ }^{1}$ Professora do ICA - Universidade Federal do Ceará. Professora da Pós-Graduação em Psicologia. Brasileira, residente em Fortaleza-CE. E-mail: deborahantunes@ufc.br 
existiu, o instante do passado é retido de modo que não pode levar ao presente, ao contrário do passado de fato vivido.

Em Sobre fotografia, Susan Sontag reúne ensaios sobre suas reflexões filosófico-fotográficas sobre a evolução histórica da fotografia, bem como a relação conturbada entre espectadores e fotógrafos com as imagens. Uma das críticas feitas pela autora aponta que o erro dos surrealistas, que acolheram a fotografia em certo momento histórico, foi imaginar que o surreal fosse universal, ao passo que ele se revelou extremamente referenciado no que diz respeito aos seus traços históricos, étnicos e restritos a uma classe. Acreditavam que as imagens reveladas pelo fotografar seriam do seu inconsciente, cujo conteúdo seria intemporal e universal, "[...] o que torna uma foto surreal é o seu páthos irrefutável como mensagem do passado e a concretude de suas sugestões a respeito da classe social" (SONTAG, 2017, 35).

Embora a fotografia seja recorte de um dado momento histórico e provoque reflexões particulares sobre a imagem, há algo de intraduzível e incomunicável. Na fotografia há uma relação especulativa entre imagem e espectador, mas não capta o caráter irredutível da história. Sontag $(2017,15)$ diz que

[...] todas as fotos são memento mori. Tirar uma foto é participar da mortalidade, da vulnerabilidade e da mutabilidade de outra pessoa (ou coisa). Justamente por cortar uma fatia desse momento e congelá-la, toda foto testemunha a dissolução implacável do tempo.

A relação da obra de arte com o tempo faz parte de importantes reflexões que orientam parte da obra de Walter Benjamin no que diz respeito também à sua reprodutibilidade técnica. Em $A$ obra de arte na era de sua reprodutibilidade técnica, o autor se debruça sobre investigações acerca do declínio da aura em decorrência do processo de reprodutibilidade tomando como marco o advento da fotografia. Benjamin $(1987,170)$ define aura como

[...] uma figura singular, composta de elementos espaciais e temporais: a aparição única de uma coisa distante, por mais perto que ela esteja.

${ }^{1}$ Mestranda em Psicologia - Universidade Federal do Ceará. Bolsista FUNCAP-CE. Brasileira, residente em Fortaleza - CE. E-mail: rochellyholanda@hotmail.com

${ }^{1}$ Doutorando em Psicologia - Universidade Federal do Ceará. Brasileira, residente em Fortaleza-CE. E-mail: smarcocesar@hotmail.com

${ }_{1}^{1}$ Mestrando em Psicologia - Universidade Federal do Ceará. Bolsista FUNCAP-CE. Brasileira, residente em Fortaleza - CE. E-mail: lucasamoha@gmail.com

${ }^{1}$ Professora do ICA - Universidade Federal do Ceará. Professora da Pós-Graduação em Psicologia. Brasileira, residente em Fortaleza-CE. E-mail: deborahantunes@ufc.br 
Observar, em repouso, numa tarde de verão, uma cadeia de montanhas no horizonte, ou um galho, que projeta sua sombra sobre nós. Significa respirar a aura dessas montanhas, desse galho.

Ao passo que Niépce e Daguerre traziam ao mundo a aurora de seus experimentos fotográficos, Benjamin atenta ao fato de que pela primeira vez a mão não protagoniza o processo de reprodução da imagem, que agora cabe ao olhar. A inspiração do artista estaria agora ao alcance de um botão e sua obra acontece pelo interlúdio da máquina.

Partindo desses apontamentos, é possível elaborar uma crítica à suposta pretensão da fotografia, enquanto evidência histórica ou mecanismo de intervenção social, que propõe trazer para o presente um traço histórico do passado. Quais histórias podem ser contadas pela fotografia? A imagem do menino negro no mar de Copacabana não diminui o racismo ou a segregação social no Brasil. A fotografia não carrega consigo a autenticidade, o traço histórico presente no século XX acaba se mostrando o interesse pela reprodutibilidade técnica da arte, de trazer para perto o souvenir, no entanto isso nos distancia da experiência coletiva, do hic et nunc que preenche a arte de significado. "A esfera da autenticidade, como um todo, escapa À reprodutibilidade técnica, e naturalmente não apenas à técnica" (BENJAMIN, 1987, 167).

Embora se possa considerar que toda história é o entremeio narrativo entre fictício e científico, fotografar pode ser uma formação discursiva que necessita não só do factual (a imagem em si), mas do subjetivo. No entanto, mesmo esse construto discursivo não dá conta do "resto" e é através do que é intraduzível que nos é permitido avançar na história.

\section{CONCLUSÃO}

Pode parecer estranho pensar em "resto" daquilo que aparece retratado em uma fotografia. O ditado segundo o qual "uma imagem fala mais do que mil palavras" nos leva ao engano de que é possível fixar um determinado momento,

${ }^{1}$ Mestranda em Psicologia - Universidade Federal do Ceará. Bolsista FUNCAP-CE. Brasileira, residente em Fortaleza - CE. E-mail: rochellyholanda@hotmail.com

${ }^{1}$ Doutorando em Psicologia - Universidade Federal do Ceará. Brasileira, residente em Fortaleza - CE. E-mail: smarcocesar@hotmail.com

${ }_{1}^{1}$ Mestrando em Psicologia - Universidade Federal do Ceará. Bolsista FUNCAP-CE. Brasileira, residente em Fortaleza - CE. E-mail: lucasamoha@gmail.com 
objeto ou pessoa sem realizar contra ele uma violência; violência que passa a ser reproduzida na naturalização da técnica, na pretensão de dominação, de captura desse momento, objeto ou pessoa.

Tal qual os conceitos, dos quais lançamos mão para dominar determinado assunto ou conhecimento, a imagem capturada é sempre mais e menos do que aquilo a que ela se refere. Como memento mori, ela congela dada realidade e não consegue abarcar a vida que ali pulsa e que é marcada pelo ritmo da história. A imagem é mais do que o que é capaz de capturar porque traz em si mesma, através da técnica sedimentada no ato de sua realização, toda a história - o que inclui a dialética da civilização e da barbárie. Por outro lado, ela é menos do que aquilo que retrata, porque fixa como invariante a vida que está em movimento, escondendo as múltiplas possibilidades tanto de seu aqui e agora, quanto de seu devir

Ao fixar um momento, a fotografia nos fornece um documento da história. Ao recortar esse momento na dependência do olhar do fotógrafo, ela aproximase da criação, da ficção - seja pelo enquadramento realizado na hora do click, seja pela utilização de edições a posteriori. Ao fazer isso a partir das mais avançadas técnicas, produz conhecimento que, para escapar do fetiche da mercadoria, precisa reconhecer seu estado no momento histórico presente. A aproximação entre história, ficção e conhecimento - e não qualquer desses elementos em separado - na fotografia revela seu potencial estético na medida em que se afasta dela o olhar ingênuo e crédulo que, via de regra, é incapaz tanto de criar, quanto de decifrar as imagens a favor da reprodução - via técnica - do existente. Aqui a contradição existente em toda e qualquer obra fotográfica não é eliminada, mas reconhecida como possibilidade de superação na forma de produção do que (não)existe.

\footnotetext{
${ }^{1}$ Mestranda em Psicologia - Universidade Federal do Ceará. Bolsista FUNCAP-CE. Brasileira, residente em Fortaleza - CE. E-mail: rochellyholanda@hotmail.com

${ }^{1}$ Doutorando em Psicologia - Universidade Federal do Ceará. Brasileira, residente em Fortaleza - CE. E-mail: smarcocesar@hotmail.com

${ }^{1}$ Mestrando em Psicologia - Universidade Federal do Ceará. Bolsista FUNCAP-CE. Brasileira, residente em Fortaleza - CE. E-mail: lucasamoha@gmail.com 


\section{REFERÊNCIAS}

ADORNO, Theodor W, HORKHEIMER, Max. A dialética do esclarecimento. Rio de Janeiro: Jorge Zahar Editor, 1995.

BARTHES, Roland. A Câmara clara: nota sobre a fotografia. Tradução de Júlio Castañon Guimarães. Rio de Janeiro: Nova Fronteira, 1984.

BENJAMIN, Walter. Origem do drama barroco alemão. Tradução de Sergio Paulo Rouanet. São Paulo: Brasiliense, 1984.

BENJAMIN, Walter. Magia e técnica, arte e política: obras escolhidas. São Paulo: Brasiliense, 1987.

BERGER, John. Para entender uma fotografia. São Paulo: Companhia das Letras, 2017.

CERTEAU, Michel. A História e Psicanálise: entre Ciência e Ficção. Belo Horizonte: Autêntica Editora/Coleção História e Historiografia, 2016.

FLUSSER, Vilém. Filosofia da caixa preta: ensaios para uma futura filosofia da fotografia. São Paulo: Hucitec, 1985.

FLUSSER, Vilém. Pós-História: vinte instantâneos e um modo de usar. São Paulo, Duas Cidades. Reedição: São Paulo: Annablume, 2011.

FRANCO, Renato. O valor cognitivo do cinema e das imagens segundo Walter Benjamin. Constelaciones. Revista de Teoría Crítica, v. 6, n. 6, p. 322-329, 2014.

HANKE, Michael. A comunicologia segundo Vilém Flusser. Galáxia - Revista do Programa de Pós-Graduação em Comunicação e Semiótica, São Paulo, n. 7, p. 59-72, abr. 2004.

${ }^{1}$ Mestranda em Psicologia - Universidade Federal do Ceará. Bolsista FUNCAP-CE. Brasileira, residente em Fortaleza - CE. E-mail: rochellyholanda@hotmail.com

${ }^{1}$ Doutorando em Psicologia - Universidade Federal do Ceará. Brasileira, residente em Fortaleza - CE. E-mail: smarcocesar@hotmail.com

${ }^{1}$ Mestrando em Psicologia - Universidade Federal do Ceará. Bolsista FUNCAP-CE. Brasileira, residente em Fortaleza - CE. E-mail: lucasamoha@gmail.com 
HEIDEGGER, Martin. A questão da técnica. ScientiaeStudia, São Paulo, v. 5, n. 3, p. 375-98, 2007.

JONAS, Hans. Ensaios Filosóficos. São Paulo: Paulus, 2017.

ORELLANA, Rodrigo Castro. Michel de Certeau: história e ficção. Princípios: Revista de Filosofia (UFRN), v. 19, n. 31, p. 5-27, 2012.

SONTAG, Susan. Sobre fotografia. São Paulo: Companhia das Letras, 2017.

${ }^{1}$ Mestranda em Psicologia - Universidade Federal do Ceará. Bolsista FUNCAP-CE. Brasileira, residente em Fortaleza - CE. E-mail: rochellyholanda@hotmail.com

${ }^{1}$ Doutorando em Psicologia - Universidade Federal do Ceará. Brasileira, residente em Fortaleza - CE. E-mail: smarcocesar@hotmail.com

${ }^{1}$ Mestrando em Psicologia - Universidade Federal do Ceará. Bolsista FUNCAP-CE. Brasileira, residente em Fortaleza - CE. E-mail: lucasamoha@gmail.com

${ }^{1}$ Professora do ICA - Universidade Federal do Ceará. Professora da Pós-Graduação em Psicologia. Brasileira, residente em Fortaleza - CE. E-mail: deborahantunes@ufc.br 